\title{
IGUALDADE DE GÊNERO E POLÍTICAS MACROECONÔMICAS
}

\author{
Bila Sorj \\ Universidade Federal do Rio de Janeiro, Rio de Janeiro, Brasil
}

\begin{abstract}
Resumo: O presente artigo tem como objetivo realizar uma leitura crítica do relatório da ONUMulher intitulado Progress of the World's Women 2015-2016. Transforming Economies, Realizing Rights. Após argumentar que o documento se distingue por ter como referência analítica as ricas contribuições dos estudos feministas na discussão das desigualdades de gênero, procurase identificar algumas lacunas no documento, notadamente, a ausência de debate sobre as migrações internacionais e a mobilidade urbana que incidem sobre as desigualdades de classe e gênero.
\end{abstract}

Palavras-chove: Igualdade de gênero; economia; estudos feministas.

O relatório Progress of the World's Women 2015-2016. Transforming Economies, Realizing Rights da ONU-Mulheres é muito bem-vindo, sobretudo, no momento atual de crise econômica global que tem como consequência o aumento das desigualdades e das vulnerabilidades sociais. A elaboração de um relatório analítico e propositivo cujo mote é "transformar as economias" a fim de avançar a igualdade de gênero é extremamente relevante para governos, organizações da sociedade civil, pesquisadoras, pesquisadores e ativistas que estão discutindo e agindo para a superação da crise atual.

O relatório é claramente baseado nas contribuições de estudiosas feministas de várias procedências disciplinares que assumem como referência analítica o conceito de "igualdade substantiva". Se as conquistas legais, que garantem a igualdade formal entre homens e mulheres são indiscutivelmente importantes, sua incorporação nas práticas econômicas, sociais e políticas tem se mostrado pouco presente. O conceito de "igualdade substantiva" remete, justamente, para a presença de barreiras estruturais e normas discriminatórias de gênero que reproduzem desigualdades e que precisam ser entendidas e removidas.

Conferir ao conceito de igualdade substantiva um papel analítico maior e abordálo como um princípio dos direitos humanos permite redefinir o entendimento que as agências internacionais e multilaterais têm da questão da igualdade de gênero. Em tais documentos, a igualdade de gênero normalmente é acionada como um imperativo do desenvolvimento,

cC) (7) Esta obra está sob licença Creative Commons. 
dispositivo de valor instrumental que permite a ampliação das capacidades humanas. Tal razão instrumental não desapareceu completamente deste relatório, na medida em que somos informados que "as crescentes desigualdades entre grupos sociais, e entre as mulheres ricas e pobres, prejudicam o desenvolvimento, desperdiçando capacidades e talentos humanos, dificultando o dinamismo econômico e ameaçando a coesão social" (UN WOMEN, 2015 , p. 234, tradução nossa). Todavia, essa abordagem ocupa, de fato, um espaço menor e ganha centralidade em enunciados que afirmam ser a igualdade de gênero um valor em si mesmo, uma obrigação dos diretos humanos que permanece amplamente descumprida. Para se alcançar a igualdade substantiva, o relatório propõe que as políticas econômicas de crescimento e as políticas sociais de promoção da igualdade de gênero devem trabalhar in tandem. Isso quer dizer que as políticas sociais devem deixar de ser uma forma de compensar os efeitos indesejáveis das políticas macroeconômicas. Propõese, ao contrário, que as políticas macroeconômicas sejam em si mesmas formuladas visando a igualdade de gênero e a justiça social.

O relatório também é muito bem-vindo sobretudo neste momento em que a crise econômica vem sendo enfrentada com políticas de austeridade, que impõe severos cortes nos gastos públicos. O documento, na contramão dessas políticas, preconiza que para corrigir as desvantagens socioeconômicas das mulheres é necessário fortalecer as políticas sociais, com políticas de emprego, de proteção social e serviços sociais de natureza universal. Essa advertência é dirigida a todas as economias do mundo, dos países do Norte e do Sul, mas é, sobretudo, relevante aos países que adotaram políticas de combate à pobreza como os programas de transferência condicionada de renda, do tipo do nosso Bolsa Família, e que se converteram em panaceia para as soluções dos problemas da pobreza. De fato, a experiência brasileira parece mostrar que esses programas, apesar de contribuírem para a redução da pobreza extrema, não foram acompanhados de uma expansão significativa dos serviços públicos indispensáveis para reduzir a pobreza e as desigualdades de gênero, tais como educação, saúde, capacitação profissional permanente, segurança e moradia (Lena LAVINAS, 2013).

Outra contribuição notável do relatório se refere à noção de que o trabalho remunerado só se torna um pilar fundamental para a igualdade substantiva das mulheres quando o trabalho doméstico e de cuidado é compartilhado entre homens e mulheres, quando permite as mulheres dispor de um tempo para o ócio e ao aprendizado; quando proporciona renda suficiente para manter um nível de vida adequado e quando as mulheres são tratadas dignamente no trabalho. Na realidade, como muitos estudos no país mostram (Bila SORJ, 2004; Maria Cristina A. BRUSCHINI; Arlene Martinez RICOLDI, 2009) a persistência das desvantagens das mulheres no mercado de trabalho ocorre, em boa medida, porque o trabalho doméstico e de cuidado não remunerado é uma limitação importante à capacidade das mulheres de se engajarem no trabalho remunerado. Em muitos países, quando se combina o trabalho pago com o trabalho não-pago, a carga global de trabalho das mulheres é mais alta do que dos homens. O relatório sugere que, para corrigir essa desigualdade, sejam realizadas mudanças na forma como ambos - o trabalho remunerado e o trabalho de cuidado e doméstico não remunerado - são organizados. Em relação a este último, o documento é mais detalhado e recomenda um conjunto de políticas que reduzem e redistribuem, com os homens e a sociedade, o trabalho doméstico e de cuidado, como investimentos em infraestrutura e em serviços, ampliação do acesso a creches, ampliação das licenças maternidade, paternidade e parental, inclusive para os trabalhadores informais. Todavia, o relatório não desenvolve quais seriam as mudanças necessárias na organização do mercado de trabalho, para além de uma vaga afirmação como:

618 Estudos Feministas, Florianópolis, 24(2): 617-620, maio-agosto/2016 
enquanto os mercados de trabalho continuarem a operar com base em expectativas de empregos ininterruptos, em tempo integral e para a vida toda, aqueles que realizam a maior parte do trabalho doméstico e de cuidado não remunerado serão inevitavelmente penalizados. (UN WOMEN, 2015, p. 73, tradução nossa).

Todavia, o mundo do trabalho vem sofrendo grandes transformações. A passagem de um modelo fordista/taylorista de produção para um sistema de acumulação flexível contribuiu para o crescimento do trabalho subcontratado, por conta própria, sendo cada vez mais comuns os contratos de trabalho por tempo determinado e em tempo parcial, sobretudo para as mulheres. O relatório não avança em propostas concretas sobre as reformas desejáveis na organização do mercado de trabalho do ponto de vista da igualdade de gênero.

É também notável a ausência de menção aos problemas de mobilidade urbana, ou seja, da capacidade dos indivíduos se moverem de um lugar para outro dentro das cidades, sobretudo da casa para o trabalho, como uma dimensão relevante na definição do que seria "trabalho decente". Esse é um problema que tende a se agravar uma vez que as projeções para o ano 2030 indicam uma maioria de população urbana $(60 \%)$ sobre a rural (40\%) no mundo e um aumento significativo da população residente em megacidades (THE ECONOMIST, 2015). As áreas que concentram a maioria dos postos de trabalho estão, em geral, localizadas nos espaços urbanas centrais e as residências da população de baixa renda estão concentradas nas periferias. Essa forma de ocupação do espaço impoe a esses trabalhadores maiores necessidades de deslocamento, o que compromete muitas horas diárias no percurso domicílio-trabalho-domicílio. As mulheres são particularmente penalizadas, pois, diante dessa configuração urbana, suas opções de trabalho ficam mais reduzidas, porquanto são as principais responsáveis pelo trabalho de reprodução do núcleo familiar. Nesse sentido, alguns movimentos sociais urbanos no Brasil estão reivindicando que as horas gastas com deslocamento sejam computadas como trabalho produtivo não pago (PASSA PALAVRA, 2014).

Um tema que mereceria mais atenção se refere ao processo de mercantilização e globalização do trabalho de cuidado e sua relação com os direitos humanos. Trata-se de um novo mercado de trabalho em expansão que responde ao aumento da duração da vida, dando novos sentidos aos fluxos migratórios. As migrações internacionais se feminizam, o emprego se precariza e as desigualdades entre mulheres de diferentes classes sociais, raças/etnias e nacionalidades aumentam (Barbara EHRENREICH; Arlie Russell HOCHSCHILD, 2002). Os desafios de inclusão dessas trabalhadoras na categoria de trabalho decente são imensos e foram muito bem formulados por Judy Fudge (2013), que advoga pela expansão do alcance das leis trabalhistas e que deixem de permanecer identificadas ao território do estado-nação. Em outras palavras, trata-se de desenvolver fundamentos normativos para que as leis do trabalho não fiquem confinadas às concepções estreitas da cidadania nacional. Esse é certamente um grande desafio para a igualdade de gênero e também para a igualdade entre as mulheres na economia do cuidado.

O ponto mais fraco do relatório são os relatos de experiências localizadas, pontuais de mudança social consideradas bem-sucedidas que são denominadas como "histórias de mudança" (stories of change). Esse estilo narrativo individualizado, tão comum aos documentos das Nações Unidas e de muitas ONGs, é especialmente destoante do conteúdo deste relatório, que enfatiza processos e mudanças estruturais de amplo alcance. Os casos relatados são experiências microssociais e muito referidas à história da sociedade que as produziu. Guardam intrínseca conexão com o universo político, social e cultural que é próprio de uma determinada realidade. Nenhuma experiência pontual é possível de ser transportada mecanicamente. Os casos tratados descrevem situações aparentemente bemsucedidas, mas que são difíceis de serem generalizadas para outras realidades regionais. 
Finalmente, o documento apresenta muitos dados estatísticos que são um instrumento importante para se avaliar a evolução das desigualdades de gênero globalmente. 0 relatório avalia que muito se avançou desde 1980, na sequência da proclamação pelas Nações Unidas da Década das Mulheres: Igualdade, Desenvolvimento e Paz (1976-1985). Mas reconhece que faltam muitos dados sobre desigualdade de gênero em áreas muito importantes e que as informações sobre os países em desenvolvimento são ainda muito limitadas. Com certeza, uma das grandes contribuições deste documento é a de influenciar os estados nacionais a aperfeiçoarem seus sistemas estatísticos de modo a gerar evidências sobre o progresso da igualdade de gênero nas suas respectivas sociedades. Entretanto, o principal mérito do relatório consiste na adoção de um marco interpretativo inovador, no qual as políticas macroeconômicas devem ser, em si mesmas, um instrumento para avançar a igualdade de gênero e a justiça social. Certamente, esse foi um dos principais ensinamentos que aprendemos com as economistas feministas e que, finalmente, foi incorporado ao mais recente relatório da ONU-Mulheres.

\section{Referências}

BRUSCHINI, Maria Cristina A.; RICOLDI, Arlene Martinez. "Família e Trabalho: difícil conciliação para mães trabalhadoras de baixa renda". Cadernos de Pesquisa, v. 39, n. 136, p. 93123, jan./abr. 2009.

EHRENREICH, Barbara; HOCHSCHILD, Arlie Russell. Global Woman: Nannies, Maids and Sex Workers in the New Economy. New York: Metropolitan Press, 2002.

FUDGE, Judy. Commodifying Care Work: Globalization, Gender and Labour Law. Labour Law Research Network Inaugural Conference, Barcelona, june 13-15, 2013, Available from: $<w w w . u p f . e d u / g r e d t i s s /$ pdf/2013-LLRNConf Fudge.pdf $>$. Access on 02/02/2016.

LAVINAS, Lena. "21 th Century Welfare”. New Left Review 84, p. 5-40, nov.-dec. 2013.

PASSA PALAVRA. Mobilidade Urbana como Problema, 10 de janeiro de 2014. Disponível em: <http://www.passapalavra.info/2014/01/90364>. Acesso em 02/02/2016.

SORJ, Bila. Reconciling work and family; issues and policies in Brazil. Geneva: International Labour Office, 2004. (Condition of work and employment series, 8)

THE ECONOMIST. Urbanization and the Rise of the Megacity. Feb. 4th 2015. Available from: $<$ http://www.economist.com/blogs/graphicdetail/2015/02/daily-chart-1 > . Access on 02/ 02/2016.

UN WOMEN. Progress of the World's Women 2015-2016. Transforming Economies, Realizing Rights. New York: United Nations, 2015. Available from: <http://progress.unwomen.org/ en/2015/pdf/UNW_progressreport.pdf $>$. Access on 02/02/2016.

[Dossiê proposto em 6/07/2015, apresentado em 12/01/2016 aceito para publicação em 29/02/2016]

Gender Equality and Macroeconomics Policies

Abstract: This article aims to make a critical reading of the report Progress of the World's Women 2015-2016. Transforming Economies, Realizing Rights of UN-Women. After arguing that the report is distinguished by having as analytical reference the rich contributions of feminist studies in the discussion of gender inequalities, it tries to point out some shortcomings, namely, the absence of debate on international migration and urban mobility that severely affect class and gender inequalities.

Keywords: Gender Equality; Economy; Feminist Studies. 